SECTION 20. Medicine.

Dudareva Larisa Andreyevna candidate of medical Sciences, assistant of the chair of propedeutics of internal diseases Rostov state medical University of the health Ministry of health of Russia

Bokhanova Elena Grigoryevna candidate of medical Sciences, assistant of the chair of propedeutics of internal diseases Rostov state medical University of the health Ministry of health of Russia

Ter-Akopyan Aleksandra Ovanesovna student of the 5th course of treatment-prophylactic faculty Rostov state medical University of the health Ministry of health of Russia

Tereshenkova Yana Olegovna student of the 5th course of treatment-prophylactic faculty Rostov state medical University of the health Ministry of health of Russia

\title{
IDENTIFICATION OF RISK GROUPS ON THE DEVELOPMENT OF CHRONIC TUBULO-INTERSTITIAL NEPHRITIS, INDUCED INTAKE OF NONSTEROIDAL ANTI-INFLAMMATORY DRUGS AMONG PATIENTS.
}

This article is devoted to the problem of early diagnosis of interstitial lesions of the kidneys and, first of all chronic tubulo-interstitial nephritis, induced intake of nonsteroidal antiinflammatory drugs.

Keywords: nephritis, anti-inflammatory drugs, hospital.

\section{ВЫЯВЛЕНИЕ ГРУПП РИСКА ПО РАЗВИТИЮ ХРОНИЧЕСКОГО ТУБУЛО-ИНТЕРСТИЦИАЛЬНОГО НЕФРИТА, ИНДУЦИРОВАННОГО ПРИЕМОМ НЕСТЕРОИДНЫХ ПРОТИВОВОСПАЛИТЕЛЬНЫХ ПРЕПАРАТОВ, СРЕДИ ПАЦИЕНТОВ СТАЦИОНАРА.}

\begin{abstract}
Данная статья посвящена проблеме ранней диагностики интерстициальных поражений почек и, прежде всего хронического тубуло-интерстициального нефрита, индуцированного приѐмом нестероидных противовоспалительных препаратов.

Ключевые слова: нефрит, противовоспалительные препараты, стациионар.
\end{abstract}


Нестероидные противовоспалительные препараты (НПВП) относятся к числу самых распространенных лекарственных средств. Его широко используют в медицинской практике разных стран для лечения воспалительных заболеваний и купирования болевых синдромов [3, с. 17]. В то же время, применение данной группы лекарственных препаратов ассоциируется с широким спектром побочных эффектов, что увеличивает число лекарственно-обусловленных заболеваний (ятрогений). Данная статья посвящена проблеме ранней диагностики интерстициальных поражений почек и, прежде всего хронического тубуло-интерстициального нефрита (ХТИН), индуцированного приѐмом НПВП. Причинами развития данной патологии, именуемой также «аналгетической нефропатией», предположительно является блокада синтеза почечных простагландинов, регулирующих гемодинамику с развитием ишемических изменений в ткани почек, снижением клубочковой фильтрации и нарушением водно солевого баланса [2, с. 269]. Для Российской Федерации лекарственная патология, индуцированная приемом НПВП, в настоящее время приобретает масштабы национальной трагедии, поскольку имеет место бесконтрольный прием данной группы препаратов. Аналгетическая нефропатия диагностируется на поздней стадии, когда все изменения носят необратимый характер. [1, с. 28]. Нами проведено скрининговое исследование выявление частоты изменений мочевого осадка, патология которого является одним из клинических проявлений интерстициального нефрита, с дозой аналгетических препаратов, принятых пациентами в течение жизни.

Для реализации поставленной задачи нами обследованы пациенты отделений различного профиля в ФГБУЗ ЮОМЦ ФМБА России. Общая выборка составила 500 человек. Опрос проводился по специально разработанной анкете, учитывающий селективность и неселективность принятых ранее препаратов, длительность и кратность их приема, а также итоговые дозы НПВП, принятых в течение жизни пациента. Среди обследованных лих только 6,5 \% отрицали употребление аналгетических препаратов. Суммарно приняли в течение жизни, по данным опроса, НПВП более 1 кг - 6,6 \% респондентов, более 0,5 кг - 7,4\% и менее 0,5 кг - $86 \%$ опрошенных. С целью выявления риска по развитию ХТИН, индуцированного приемом НПВП, все больные разделены на три группы по суммарной дозе НПВП, принятой в течении жизни: 1 группа - более 1 кг; 2 группа - 0,5 - 1 кг; 3 группа - менее 0,5 кг. Обработка данных проводилась с помощью пакета прикладных программ Statistica 6.0.

В первой группе (n=33) мужчин оказалось 27,2 \%; женщин - 72,8 \%. По результатам антропометрии индекс массы тела (ИМТ) в первой группе составил 29,6 кг/м2. Показатели артериального давления составили для систолического 169 мм.рт.ст. для диастолического 98 мм.рт.ст. Среди жалоб были отмечены слабость $-72 \%$, головная боль $-70,1 \%$, боли в 
пояснице - 67,2 \%, утомляемость - 66,7 \%, отеки нижних конечностях $45,5 \%$, отеки на лице - 36,3 \%, тошнота - 34,6 \%. Среди причин приема НПВП в 1 группе пациенты указали ИБС - 7 \%, деформирующий артроз $27,9 \%$, остеохондроз - 6\%, краниалгию - 6,7 \% (без назначения врача). Пациенты 1 группы, по данным истории болезней, имели следующие сопутствующие заболевания: ИБС - 63,6 \%, хроническая сердечная недостаточность - 54,5 \%, сахарный диабет - 18,3\%, анемия - 13 \%. При биохимическом исследовании крови уровень креатинина 89,9 мкм/л., мочевины - 6,78 мм/л. По данным анализа мочи: протеинурия отмечена у $15,1 \%$ пациентов, гематурия - 9 \%, эпителийурия - 35 \%. Скорость клубочковой фильтрации подсчитана по формуле Кокрофта-Голта и равна 80,9 мл/мин.

Во второй группе (n=36) мужчин оказалось 33,4 \%; женщин - 66,6 \%. По результатам антропометрии индекс массы тела (ИМТ) во второй группе составил 30,1 кг/м2. Показатели артериального давления систолического 166 мм.рт.ст., диастолического 97 мм.рт.ст. Среди жалоб были отмечены слабость - 61,6 \%, головная боль - 52,7 \%, боли в пояснице - 58,3\%, утомляемость - 23,4\%, отеки на лице - $25 \%$. Среди причин приема НПВП во 2 группе пациенты указали ИБС - 55,8 \%, деформирующий артроз - 30,9 \%, остеохондроз - 7,5\%, краниалгию -45,2 \% (без назначения врача). Пациенты 2 группы, по данным истории болезней, имели следующие сопутствующие заболевания: ИБС - 66,6 \%, хроническая сердечная недостаточность - 57,5 \%, анемия - 8,3 \%. При лабораторном исследовании крови уровень креатинина 84,1 мкм/л., мочевины - 7,17 мм/л. По данным анализа мочи: протеинурия отмечена у 8,3 \% пациентов, гематурия - 6,4 \%, эпителийурия - 19,4\%. Скорость клубочковой фильтрации подсчитана по формуле Кокрофта-Голта и равна 83,2 мл/мин.

В третьей группе (n=419) мужчин оказалось 37,9 \%; женщин - 62,1\%. По результатам антропометрии индекс массы тела (ИМТ) во второй группе составил 29,1 кг/м2. Показатели артериального давления были: систолического 146 мм.рт.ст., диастолического 92 мм.рт.ст. Среди жалоб были отмечены слабость - 62,5\%, головная боль $-54,7 \%$, боли в пояснице $-58,3 \%$, утомляемость - 23,4\%, отеки нижних конечностях 35,2 \%, отеки на лице - 24,2 \%. Среди причин приема НПВП в 3 группе пациенты указали ИБС $-17,8$ \%, деформирующий артроз - 20,7 \%, хроническая ишемия конечностей $-1,24 \%$, остеохондроз - 7,5\%, краниалгия $-48,5 \%$ (без назначения врача). Пациенты 3 группы, по данным истории болезней, имели следующие сопутствующие заболевания: ИБС - 36,4 \%, хроническая сердечная недостаточность - 32,3\%, сахарный диабет $18,1 \%$, анемия - 8,8 \%. При лабораторном исследовании крови уровень креатинина 93,1 мкм/л., мочевины - 6,9 мм/л. По данным анализа мочи: протеинурия отмечена у 1,2 \% пациентов, гематурия - 3,1 \%, 
Эпителийурия - 6,3 \%. Скорость клубочковой фильтрации подсчитана по формуле Кокрофта-Голта и равна 94,2 мл/мин.

Таким образом, в первой и второй группах значительно чаще отмечалось отклонение в мочевом осадке. Такие больные находятся в группе риска по развитию ХТИН, что связано с длительностью и дозой аналгетика, принятого на протяжении жизни.

Результаты данного клинико-эпидемиологического исследования указывают на важность тщательного сбора анамнеза на предмет употребления НПВП пациентами, что позволит своевренно выявлять группы риска по развитию ХТИН.

\section{Список литературы}

1. Шишкин А.Н. Анальгетическая нефропатия: скрытая угроза // Новые С-Пб врачебные ведомости - 2003 - №2 - C. 28-31

2. Dennen P. Biomarkers of acute kidney injury 2007 - Vol 68. №5 - P. 269278

3. Singh G. Epidemiology of NSAID indused gastrointestinal complications / 2008 Vol 56. №5 - P. 17-24 